\title{
Ocular Changes During Pregnancy
}

\section{Alterações oftalmológicas na gravidez}

\author{
Pedro Marcos-Figueiredo ${ }^{1}$ Ana Marcos-Figueiredo ${ }^{2}$ Pedro Menéres ${ }^{2,3}$ Jorge Braga 3,4
}

${ }^{1}$ Hospital Senhora da Oliveira (HSO), Guimarães, Portugal

${ }^{2}$ Centro Hospitalar do Porto (CHP), Porto, Portugal

${ }^{3}$ Instituto de Ciências Biomédicas de Abel Salazar da Universidade do Porto (ICBAS-UP), Porto, Portugal

${ }^{4}$ Centro Materno-Infantil do Norte (CMIN), CHP, Porto, Portugal
Address for correspondence Pedro Figueiredo, MD, Hospital Senhora da Oliveira (HSO), Rua dos Cutileiros, Creixomil 4835-044, Guimarães, Portugal (e-mail: pedrofigueiredoficial@gmail.com).

Rev Bras Ginecol Obstet 2018;40:32-42.

\begin{abstract}
Pregnancy is needed for the perpetuation of the human species, and it leads to physiological adaptations of the various maternal organs and systems. The eye, although a closed space, also undergoes some modifications, most of which are relatively innocuous, but they may occasionally become pathological. For women, pregnancy is a susceptibility period; however, for many obstetricians, their knowledge

Keywords

- pregnancy

- ophthalmology

- eye medication

- ocular physiology

- ocular pathology

\section{Resumo}

\section{Palvras-chave}

- gravidez

- oftalmologia

- medicação ocular

- fisiologia ocular

- patologia ocular of the ocular changes that occur during pregnancy tends to be limited. For this reason, this is a important area of study as is necessary the development of guidelines to approach those changes. Of equal importance are the knowledge of the possible therapies for ophthalmological problems in this period and the evaluation of the mode of delivery in particular conditions. For this article, an extensive review of the literature was performed, and a summary of the findings is presented.

A gravidez é necessária à perpetuação da espécie humana, levando a adaptações fisiológicas dos diversos órgãos e sistemas maternos. O olho, apesar de uma cavidade fechada, sofre também algumas modificações, a maioria relativamente inócuas, que pontualmente poderão se tornar patológicas. A gravidez assume-se como um período particular de suscetibilidade para a mulher; no entanto, muitos obstetras têm conhecimento limitado sobre as alterações oftalmológicas na gravidez. Por conseguinte, impõe-se o seu estudo, bem como a elaboração de diretrizes para lidar com essas mudanças. De igual importância são o conhecimento da eventual terapêutica para problemas oftalmológicos neste período e a avaliação do tipo do parto em condições particulares. Desta forma, foi efetuada uma revisão bibliográfica extensa e apresentada uma síntese do tema.
\end{abstract}

\section{Introduction}

Physiological changes during pregnancy involve changes to the interior of the eye and to the outer ocular surface. Among the pathological alterations, several are related to gestational hypertension, such as, central serous retinopathy and occlu-

received

March 31, 2017

accepted

June 30, 2017

published online

August 7, 2017 sive vascular diseases, in addition to the evolution of preexisting pathologies. Likewise, the administration of ocular drugs, depending on the route, may undergo adaptations, justifying individualized decision-making. The timing of delivery and its potential interference in this balance also
Copyright $\odot 2018$ by Thieme Revinter

Publicações Ltda, Rio de Janeiro, Brazil
License terms

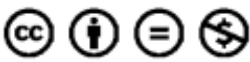


reveal remarkable interest. We performed an extensive review and summarized the existing evidence on ophthalmology and pregnancy.

\section{Methods}

We performed various literature searches on the PubMed database looking for articles published in English, French, Spanish and Portuguese. We used the terms ophthalmology and pregnancy; eye and pregnancy; ocular changes in pregnancy; ocular physiology and pregnancy; ocular diseases and pregnancy; eye and birth; ocular diseases and delivery; and eye and delivery. The inclusion criteria were studies about: the changes in ophthalmology conditions caused by pregnancy, including physiological or pathological changes; the ocular prescription in this period; and the relationship between ocular diseases and delivery. Individual studies were considered when they presented a new piece of information. We excluded from our search works regarding genetic or molecular studies.

\section{Results}

More than 1,500 articles were evaluated, and 46 fulfilled the inclusion criteria. The information was analyzed for: the consistency of the theoretical and experimental data, if applied; the year of publication (which was not an exclusion criterion); and the quality of the study.

\section{Physiological Changes}

Most ocular changes during pregnancy have hormonal, metabolic, immunological, hematological and cardiovascular origin. ${ }^{1}$

\section{Eyebrows/Chloasma}

Increased periocular pigmentation is one of the most common physiological changes, known as melasma or chloasma. ${ }^{2}$ Increased skin pigmentation occurs in $90 \%$ of pregnant women, with the proportion of chloasma ("pregnancy mask") variable (5-70\%). ${ }^{3}$ It is usually limited to the malar region, but it may include the eyebrows. ${ }^{4}$ They are reversible, and decrease gradually after delivery (and are rarely associated with thyroid disease).

\section{Tear Film}

Pregnancy conditions a modification in the physiology of the tear film, due to hormonal changes and disruption of acinar cells, producing dry eye syndrome. ${ }^{2,4}$

\section{Pupil}

The photopic and mesopic diameters of the pupil appear to increase during pregnancy (not increasing wavelength aberrations), mainly in the third trimester. It has been postulated that this is due to increased sympathetic activity. ${ }^{5}$

\section{Cornea}

The cornea, which acts as a barrier, may show a decrease in sensitivity, ${ }^{1,2,6-8}$ an increase in thickness ${ }^{8}$ (minimal, due to edema), and an increase in curvature during pregnancy, ${ }^{1,2,8}$ causing temporary refractive changes. ${ }^{2,9}$ All of these factors may contribute to contact lens intolerance (or the need to use more flat lenses). ${ }^{4}$ This is common in pregnant women, even if the lenses have been used for several years. ${ }^{2}$ This occurs mainly in the second and third trimesters, ${ }^{10}$ and pregnancy is considered a contraindication to ophthalmic surgery. ${ }^{1}$ Postpartum, these physiological changes tend to reverse, usually in the first two months, and it is advised to only consider lens upgrade or refractive surgery after this period. ${ }^{2,4,9}$

\section{Lens}

A transient loss of accommodation may occur during pregnancy and lactation, ${ }^{4}$ and any potential surgery should be postponed until stable refraction is achieved (if the pregnancy is anticipated). ${ }^{2}$

\section{Iris}

A Krukenberg spindle (pigment deposit on the posterior cornea) can be observed in pregnant women (3\%). ${ }^{3}$ This appears to decrease in size during the third trimester until the postpartum period, ${ }^{4}$ mainly due to hormonal changes and aqueous humor dynamics. ${ }^{4}$

\section{Intraocular Pressure}

It is accepted that there is a decrease in intraocular pressure (IOP) in the second half of pregnancy, ${ }^{1,11}$ mainly in the third trimester, ${ }^{1,2}$ with a decrease in its diurnal variation compared with pre-pregnancy values ${ }^{4}$ (probably due to an increase in uveoscleral drainage and hormonal changes, decreasing the aqueous humor production). ${ }^{1,3}$ It varies in adults, being lower in the sitting position and higher in the supine position, with an inverse variation in ocular perfusion pressure. ${ }^{12}$ There is an improvement in preexisting glaucoma, with glaucomatous symptoms during gestation rarely occurring. The IOP regresses to baseline values about two months postpartum. ${ }^{1}$ Applanation tonometry or alternative methods such as Tono-pen (Reichert Technologies, Depew, NY, US) and iCare (ICare Finland Oy, Vantaa, Finland) are all valid diagnostic tools in pregnancy. ${ }^{3}$ Dynamic tonometry has already been suggested by some authors as a diagnostic test for pregnancy. ${ }^{4}$

\section{Choroid}

The choroidal thickness seems to be higher in pregnant women, ${ }^{13-16}$ mainly in the first trimester, ${ }^{17}$ with the exception of preeclampsia (PE) (equal or slightly higher than nonpregnant women). ${ }^{14,16}$ The macula appears to be unchanged. $^{15}$

\section{Visual Field}

There are visual field changes reported in pregnancy, but their etiology is unknown. ${ }^{2}$ There is a physiological increase of the pituitary gland, but this is insufficient by itself to cause a defect in the visual field, unless it is accompanied by an abnormal relationship between the optic chiasm and the pituitary gland. ${ }^{4}$ These asymptomatic changes are completely reversible postpartum. ${ }^{2}$ If symptomatic, the existence of masked tumors should be investigated. ${ }^{4}$ 


\section{Hemeralopia}

Hemeralopia (difficulty to see in bright light; daytime blindness) may also be more frequent in this period. Both the modification of the tear film and the hemeralopia may also be due to vitamin A deficiency, but supplementation does not prevent all cases, and this is controversial in pregnancy.

\section{Postpartum}

Conjunctival hemorrhage (hyposphagma) is present in 10\% of pregnant and postpartum women. The only recommended intervention is monitoring the blood pressure, because it normally resolves spontaneously. ${ }^{3}$ In - Table 1 , we summarize the ocular physiological changes during pregnancy.

\section{Pathological Changes}

\section{Pregnancy-induced Hypertension}

Almost all pregnant women present reactive changes in the retinal vessels, with clearly visible changes arising only in the context of hypertension, PE or eclampsia. ${ }^{3}$ Gestational hypertension occurs in $5-11 \%$ of pregnancies, with 40 to $100 \%$ demonstrating variable retinopathy, but less than half of these are symptomatic. ${ }^{3}$ Retinal changes are directly related to the severity of the hypertension. ${ }^{3}$ In - Table 2 we summarize the possible hypertensive ocular changes in pregnancy.

A retinal Doppler along with an assessment of the symptoms in a clinical examination demonstrated a pulsatility index compatible with vasospasm. It occurs in $50-100 \%$ of PE cases, is generally reversible, and followed by hemorrhages, cotton wool spots, and, in severe cases, retinal edema and papilledema. ${ }^{4}$ A positive correlation was established among the degree of retinopathy, the severity of PE, maternal blood pressure and fetal mortality. ${ }^{4}$ The use of magnesium sulfate in the prevention and treatment of seizures has been shown to significantly decrease this index in the posterior retinal and ciliary arteries. Observation of the ocular fundus has been shown to be of increasing importance, seeming to even predict the fetal prognosis. ${ }^{18}$ In cases of PE, the retinopathy severity appears to be linked to the level of placental insufficiency and fetal growth restriction. ${ }^{19,20}$ In the hemolysis, elevated liver enzymes, low platelet count (HELLP) syndrome, bilateral serous retinal detachment and vitreous hemorrhage may also occur. ${ }^{21}$

\section{Management}

For the mother, immediate delivery is the most beneficial treatment option; for the fetus, we must consider maturity. $^{3}$ If far from term and without severity criteria, the priority is for medical control of the hypertension and reduction in the incidence of visual abnormalities. There are no defined criteria for the cases in which terminating the pregnancy is recommended to protect the ocular health of the mother. Any proposal should be individualized and involve shared decision-making. In - Table 3, we summarize the mostly considered indications for pregnancy termination. ${ }^{4}$

\section{Punctate Inner Choroidopathy}

Punctate inner choroidopathy is a disease of women of reproductive age, and may be associated with the development of choroidal neovascular membranes during pregnancy. ${ }^{22}$ It is rare and challenging, and usually has spontaneous resolution (corticosteroid therapy may be necessary in severe cases). ${ }^{22}$

Table 1 Summary of ocular physiological changes during pregnancy

\begin{tabular}{|l|l|l|l|l|}
\hline Physiological changes & Physiology & Considerations & Trimester (+) & Prognosis \\
\hline Eyebrows/ Chloasma & $\begin{array}{l}5-70 \%, \text { increased pigmentation } \\
\text { (malar region/eyebrows) }\end{array}$ & & Third & Reversible \\
\hline Tear Film & Modified $\downarrow$ & Dry eye syndrome & Third & Reversible \\
\hline Pupil & $\uparrow$ Photopic and mesopic diameter & & Third & Reversible \\
\hline Cornea & $\begin{array}{l}\downarrow \text { Sensitivity, } \uparrow \text { thickness (minimal), } \\
\uparrow \text { curvature }\end{array}$ & Contact lens intolerance & Second/Third & Reversible \\
\hline Lens & Transient loss of accommodation & & All & Reversible \\
\hline Iris & $\begin{array}{l}3 \%, \text { Krukenberg spindle } \\
\text { (pigment deposit on the } \\
\text { posterior cornea) }\end{array}$ & & First/Second & Reversible \\
\hline Intraocular Pressure & $\downarrow$ Intraocular pressure & & Third \\
\hline Choroid & $\uparrow$ Choroidal thickness & First & Reversible \\
\hline Visual field & Minimal changes & Asymptomatic & Reversible \\
\hline Hemeralopia & Difficulty to see in bright light & & Third & Reversible \\
\hline Hyposphagma & $10 \%$, conjunctival hemorrhage & Monitoring of blood pressure & Postpartum & Reversible \\
\hline
\end{tabular}

Note: + more frequent. 
Table 2 Hypertension, pregnancy and ocular changes

\begin{tabular}{|c|c|}
\hline Ocular symptoms $^{1}$ & Ocular signs $^{1}$ \\
\hline Blurred vision & Retinal arteriolar abnormalities \\
\hline Decreased vision & $\begin{array}{l}\text { Serous retinal detachment ( } 1 \% \text { in cases of preeclampsia, } 10 \% \\
\text { in cases of eclampsia, without fetal detrimental effect) }{ }^{4}\end{array}$ \\
\hline Flashes & Ischemic optic neuropathy \\
\hline Floaters & Hypertensive retinopathy (if severe) \\
\hline Scotomas & \\
\hline Visual field defects & \\
\hline Diplopia & \\
\hline $\begin{array}{l}\text { Blindness (loss of vision with normal pupillary function and } \\
\text { ophthalmoscopic examination) is rare; it occurs in up to } 15 \% \text { of } \\
\text { the cases of preeclampsia/eclampsia, by involvement of the } \\
\text { occipital cortex. }\end{array}$ & \\
\hline \multicolumn{2}{|l|}{$\downarrow$} \\
\hline \multicolumn{2}{|c|}{$\begin{array}{l}\text { Constitute severity criteria } \\
\text { May represent features of imminent seizures in cases of preeclampsia, particularly postpartum. }{ }^{1,4}\end{array}$} \\
\hline \multicolumn{2}{|c|}{ Obstetrical assessment is imposed $\Rightarrow$ excluding preeclampsia $\Rightarrow$ ophthalmological observation. } \\
\hline \multicolumn{2}{|c|}{ Prognosis $\Rightarrow$ generally good (although scotomas may persist for months). } \\
\hline May occur only in the postpartum period, with resolution of & e detachments occurring sometimes in this period. ${ }^{3}$ \\
\hline
\end{tabular}

\section{Central Serous Retinopathy}

Central serous retinopathy is defined as spontaneous and localized serous detachment of the sensorineural retina in the macula, causing symptoms of diminished or blurred vision, central scotomas, metamorphopsia and micropsy. ${ }^{1,4}$ It mainly affects young men ( 8 to $10: 1$ woman), but $0.008 \%$ of pregnant women ( $90 \%$ of the female population affected) and can occur in any trimester of pregnancy (it is more frequent in the third). ${ }^{1,3,4}$ The etiology is unknown, but this diagnosis is made by examination, and optic coherence tomography can be considered (it does not harm the fetus). ${ }^{4}$ It usually resolves at the end of pregnancy or postpartum,, ${ }^{1,4}$ but does result in a higher probability of recurrence outside pregnancy or in a subsequent gestation. ${ }^{1}$

\section{Occlusive Vascular Diseases}

\section{Purtscher-like retinopathy}

The etiology is related to granulocyte aggregation induced by complement and vascular occlusion. It is associated with labor, postpartum and complications of the late stages of pregnancy, such as PE (as well as pancreatitis and renal

Table 3 Possible indications for pregnancy termination

- Progressive severe retinopathy

- Cotton wool spots in all quadrants, with persistent arteriolar changes

- Diabetes mellitus/renal disease causing proliferative retinopathy with risk of visual loss

- Imminent vitreous hemorrhage failure $).{ }^{4}$ Upon fundoscopy, cotton wool spots and retinal hemorrhage are observed. ${ }^{4}$ This tends to resolve spontaneously, with full recovery of vision.

\section{Disseminated intravascular coagulation}

It may occur in cases of complicated miscarriages, placental abruption, severe preeclampsia and retained products of conception. It is characterized by thrombus dissemination, with the choroid being the intraocular structure involved. ${ }^{4}$ This vascular occlusion of the capillaries leads to detachment of the retinal pigment epithelium, causing a serous detachment. ${ }^{4}$ When the scenario improves, this detachment resolves; however, epithelial alterations may persist. ${ }^{4}$

\section{Thrombotic thrombocytopenic purpura}

It may be observed in pregnancy, with thrombus deposition in the vessels, hemolytic anemia, thrombocytopenia, among others. In $10 \%$ of the cases, the ocular manifestations include retinal vascular occlusion, retinal hemorrhage, serous detachment and optic disc neovascularization. ${ }^{4}$ A picture similar to Purtscher-like retinopathy may also occur, mainly if the optic nerve vessels are involved. ${ }^{4}$

\section{Amniotic fluid embolism}

It is a serious complication of pregnancy, with an $80 \%$ mortality rate. It occurs during labor, delivery, or in the immediate postpartum period. Particulate components of amniotic fluid enter the maternal circulation, causing cardiopulmonary failure. Retinal occlusions may occur, and the central retinal artery may be involved. ${ }^{4}$ However, given the general condition and prognosis, little attention is paid to the visual prognosis. ${ }^{4}$ 


\section{Preexisting Diseases}

\section{Diabetic Retinopathy}

Around $2-5 \%$ of pregnant women have preconception diabetes. ${ }^{3}$ Pregnancy is a major and independent risk factor for the progression of the disease..$^{2-4,8}$ There are other risk factors known, ${ }^{1-3,8,23}$ such as the duration of the disease, ${ }^{2}$ metabolic control before and during pregnancy ${ }^{2,3}$ (normoglycemia prior to pregnancy improves the outcome, and poor control increases the progression, as well as a rapid normalization of blood glucose levels during pregnancy, ${ }^{2,24}$ although it is not a reason for suboptimal diabetes control in this period) ${ }^{24}$ insulin therapy, visual acuity and macular edema before pregnancy, ${ }^{3,24}$ the severity of the disease at conception, ${ }^{2,8}$ the coexistence of hypertension ${ }^{2,24}$ and $\mathrm{PE},{ }^{24,25}$ and changes in retinal flow. Glycemic control during pregnancy is associated with decreased risk of fetal macrosomia and congenital malformation. ${ }^{26}$ There is also association with increased risk of fetal loss and other obstetric complications.

In type 1 diabetes mellitus (DM), the progression seems to be higher in the first two trimesters, with regression in the third. ${ }^{24}$ The rate of progression seems to be identical in the two types of previous diabetes, with type 1 more associated with proliferative retinopathy. ${ }^{24}$ Studies suggest that retinopathy does not appear to be more severe in nulliparous than in multiparous women, so the number of births does not increase the risk of retinopathy progression. ${ }^{1,24}$ The retinopathy is less severe in women with two or more pregnancies. The exact mechanism of the pathogenesis for the progression of diabetic retinopathy (DR) during pregnancy remains controversial. $^{2}$

Retinopathy (even with macular edema) occurring during the course of pregnancy has a high rate of spontaneous regression in the third trimester or postpartum. ${ }^{2}$ This is not so evident if the pregnant woman had a prior disease. However, these women are at increased risk of progression even up to one year postpartum (with vitreous hemorrhage and retinal detachments), and ophthalmologic monitoring should continue (even if not consensual, as they are rare events). ${ }^{24}$ The associated visual symptoms are blurred vision, floaters, partial or total visual loss, and they may vary and even mimic improvement. In - Table 4, we list the preconceptional counseling and treatment for DR in this period.

The influence of pregnancy on long-term DR is still conflicting. ${ }^{24}$ There are even fewer studies on type 2 diabetes. ${ }^{24}$ With regards to gestational diabetes, there are no similar associations with DR. ${ }^{1,2,8}$

\section{Uveitis}

Uveitis is rare, with a mean age at diagnosis of 39 years. The impact of pregnancy on uveitis is not well-established. ${ }^{1,3}$ The activity of the disease in the preconception period and the existence of treatment did not influence the subsequent activity of uveitis, which seemed to return to normal in the puerperium. ${ }^{27,28}$ It is logical to be associated with fewer recurrences, ${ }^{3}$ being beneficial in syndromes such as VogtKoyanagi-Harada (bilateral granulomatous panuveitis, which tends to regress during pregnancy and postpartum), ${ }^{4}$ Behcet disease and idiopathic uveitis. ${ }^{2}$ The limited evidence available on uveitis is predominantly linked to Behcet disease. Nevertheless, women with uveitis who become pregnant should be advised of possible exacerbations in the first trimester and postpartum, and there should be more careful surveillance during these periods. ${ }^{1}$ The women who have previously had ocular toxoplasmosis, due to the potential risk of recurrence in pregnancy and vertical transmission, should be followed-up in this period. ${ }^{29,30}$ The risk of congenital toxoplasmosis is insignificant. ${ }^{4}$

\section{Antiphospholipid Syndrome}

Patients have a thrombophilic state and are susceptible to arterial or venous thrombosis. Ocular manifestations may include vascular thrombosis of the retina, choroid, and optic nerve, as well as the oculomotor nerves. ${ }^{4}$

\section{Ptosis}

Ptosis, usually aponeurotic, presents or worsens in pregnancy due to increased interstitial fluid and hormonal effects. ${ }^{3,4}$ It should be distinguished from oculomotor paralysis (with weakness of extraocular muscles, diplopia and mydriasis),

Table 4 Preconception and therapeutic approach to diabetic retinopathy during pregnancy

\begin{tabular}{|l|}
\hline Preconception - ideal \\
\hline Early patient education is fundamental. \\
\hline Pregnancies in the third decade (risk $\uparrow$ exponentially with maternal age). ${ }^{4}$ \\
\hline Stable glucose values and treatment. ${ }^{4}$ \\
\hline Severe diabetic retinopathy - risk progression $\uparrow-$ delay conception until stabilization of ocular disease. ${ }^{2}$ \\
\hline Treatment \\
\hline Referral to an ophthalmologist is mandatory. \\
\hline The treatment is the same as the one offered to non-pregnant women (except for the expectant approach, \\
which can be weighed until postpartum). ${ }^{2}$ \\
\hline Varies with disease severity at conception. ${ }^{4}$ \\
\hline Some guidelines (without large amounts of evidence, especially in developed countries). ${ }^{24}$ \\
\hline Laser or vitrectomy if needed (except in cases of macular edema). ${ }^{3}$ \\
\hline
\end{tabular}


which requires neurological evaluation. ${ }^{3}$ Reversible Horner syndrome may occur after epidural analgesia, and the occurrence of transient facial paralysis can increase three-fold. ${ }^{3}$

\section{Hyperemesis Gravidarum}

Severe pregnancy hyperemesis may lead to Wernicke encephalopathy with nystagmus and extraocular muscle paralysis, which usually improve with vitamin supplements. ${ }^{4}$

\section{Optic neuropathy}

Optic neuropathies associated with pregnancy are generally ischemic due to the hypercoagulable state of pregnancy, which is associated with an increased incidence of anterior ischemic optic neuropathy. States of severe antepartum or postpartum hemorrhage may cause posterior ischemic optic neuropathy. ${ }^{4}$

\section{Idiopathic Cranial Hypertension}

Idiopathic cranial hypertension may occur or worsen in pregnancy due to weight gain. The only recommended monitoring is the strict surveillance of weight gain. ${ }^{4}$

\section{Intraocular Tumors}

\section{Pituitary adenoma}

During pregnancy, the pituitary volume increases by 30\% due to an increase in the number of cells that secrete prolactin. Similarly, a pituitary adenoma can grow and become symptomatic during pregnancy. Headache, visual changes, bitemporal field defects and diplopia usually occur. If the pituitary adenoma is detected during pregnancy, surveillance is usually sufficient, unless the symptoms become worse. ${ }^{4}$ In this case, bromocriptine, steroids and surgery may be necessary. 4

\section{Uveal melanoma}

Some new cases or growth in pregnancy have been reported. ${ }^{4}$ The mechanism of this growth is still uncertain, and it does not seem to depend on hormonal factors (like the cutaneous melanomas). ${ }^{1,4}$ The histopathology and five-year survival rate in the few available studies are similar to those of non-pregnant women. ${ }^{31}$

\section{Choroidal osteoma}

There have been some cases reported during pregnancy. The etiology of exacerbation is unknown. Rapid growth during pregnancy and subsequent postpartum regression were documented.

\section{Meningioma}

A preexisting meningioma may manifest in the second half of pregnancy due to increased tumor growth and vascularity, and also probably due to hormonal changes. ${ }^{4}$

\section{Other Diseases}

\section{Graves' disease}

Associated thyroid ophthalmopathy may present or worsen during early pregnancy, with improvement in the third trimester and postpartum recurrence. ${ }^{1}$

\section{Posterior scleritis}

It aggravates or recurs during pregnancy, and is treated with oral corticosteroid therapy, although the use of a sub-Tenon injection of triamcinolone is preferred. ${ }^{4}$

\section{Immunological diseases}

There is an improvement in the ocular and systemic manifestations during pregnancy of sarcoidosis, spondyloarthropathies and rheumatoid arthritis, probably due to the increase in endogenous corticosteroids in this period. Postpartum recurrences are occasionally observed. ${ }^{1,4}$

In - Table 5, we analyze the ocular pathological changes during pregnancy.

\section{Eye Medications}

The corneal epithelium acts as a barrier against the penetration of topical ocular eye drops. Absorption will depend on the solubility of the drug: lipophilic drugs rapidly dissolve in it. ${ }^{32}$

\section{Eye Drops}

Most medications are considered safe during pregnancy despite the scarcity of clinical trials involving pregnant women. Topical ocular medications have reduced the maternal-fetal risk. ${ }^{4,33}$ However, topical drugs may have a systemic spread, possibly crossing the placenta and creating a potential risk for the fetus (as well as for a breastfeeding child). Although it is a complex mechanism, the absorption of a part of the eye drop through the mucosal vessels, with no firstpass metabolism exists and it may be more problematic in highly concentrated droplets. ${ }^{34}$

\section{Glaucoma}

Glaucoma is rare in pregnant women; however, controversy exists when considering pharmacology in this period. ${ }^{3}$ Beta blockers are currently recommended, and in some studies they are the first line treatment for pregnant women with glaucoma. ${ }^{3,35}$ If possible, administration in the first trimester, high doses and starting therapy 2-3 days before delivery (to avoid beta blockade in the newborn) should be avoided., ${ }^{4,32}$ Surgical therapy or laser treatment must be weighed against high doses of medication. ${ }^{32}$ In-Table $6^{36}$, we analyze other drugs that can also be considered during pregnancy if beta blockers are not effective or suitable.

\section{Steroids}

The use of topical steroids is discouraged during pregnancy, but may be necessary for visual preservation in cases of uveitis, and requires careful supervision. ${ }^{1}$ There are no studies regarding this route of administration that have proven teratogenicity in humans, perhaps due to the low dose and ocular administration. ${ }^{32}$ Systemic corticosteroids have a relative contraindication during pregnancy (especially at 9-12 weeks and in doses greater than $15 \mathrm{mg} /$ day, due to potential risk to the palate). The topical route of administration has no known teratogenic effects. ${ }^{3}$ They can be used in allergic conjunctivitis with antihistamines. ${ }^{34}$ Prednisone/ prednisolone crosses the placenta in a small percentage (10 to $20 \%$ ), while dexamethasone does so in its entirety. ${ }^{3}$ 


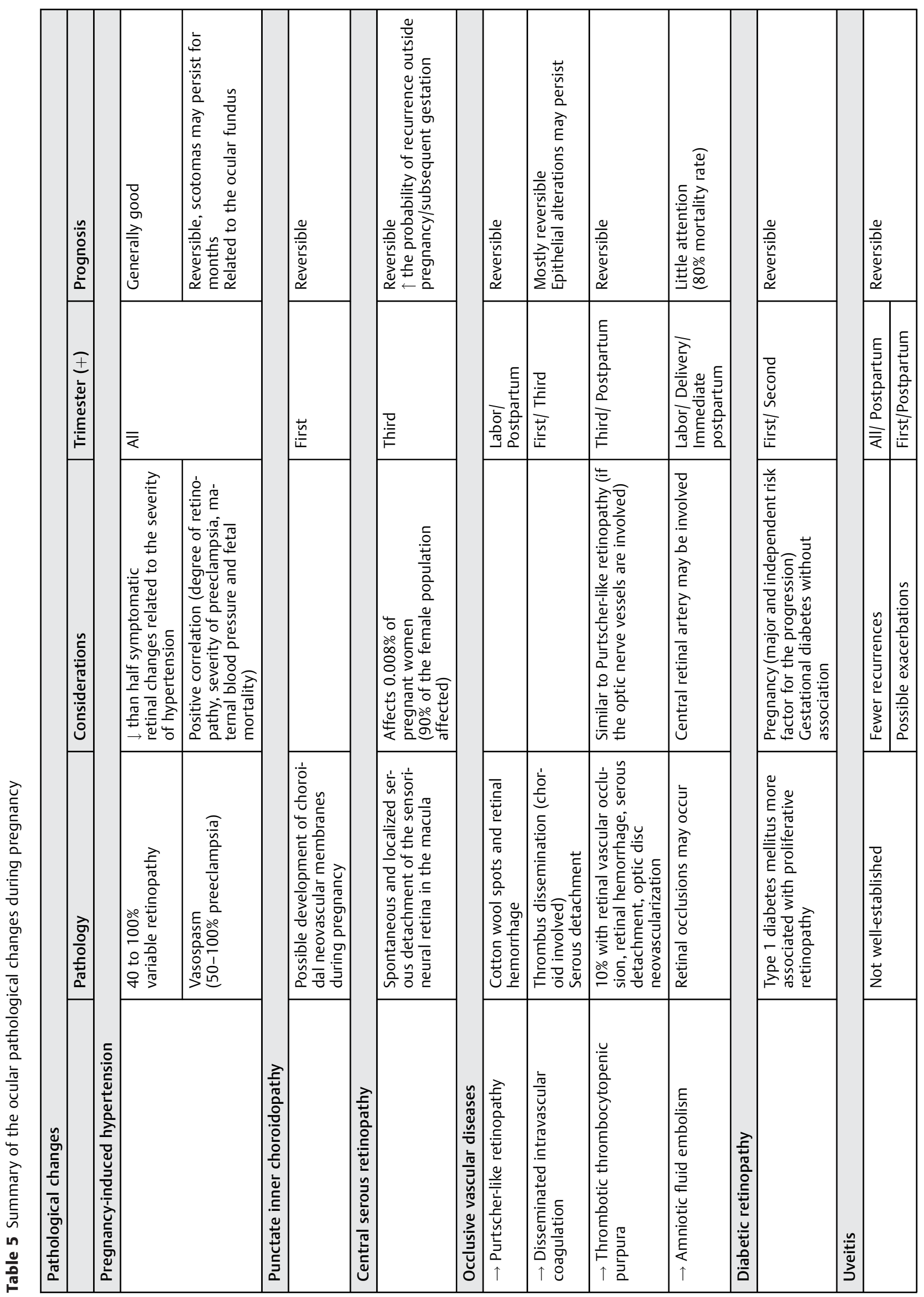




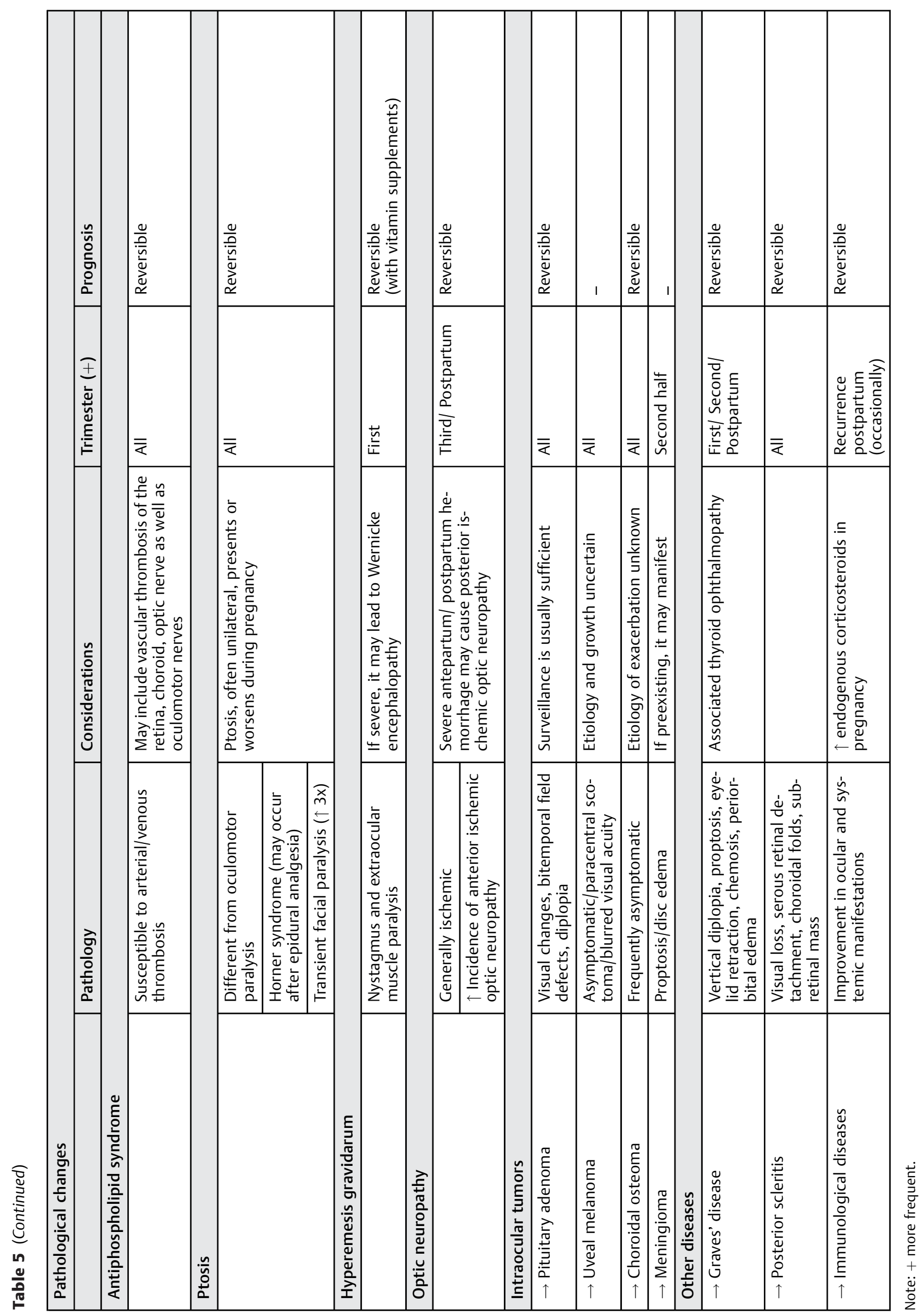


Table 6 Drugs to consider in cases of glaucoma and pregnancy

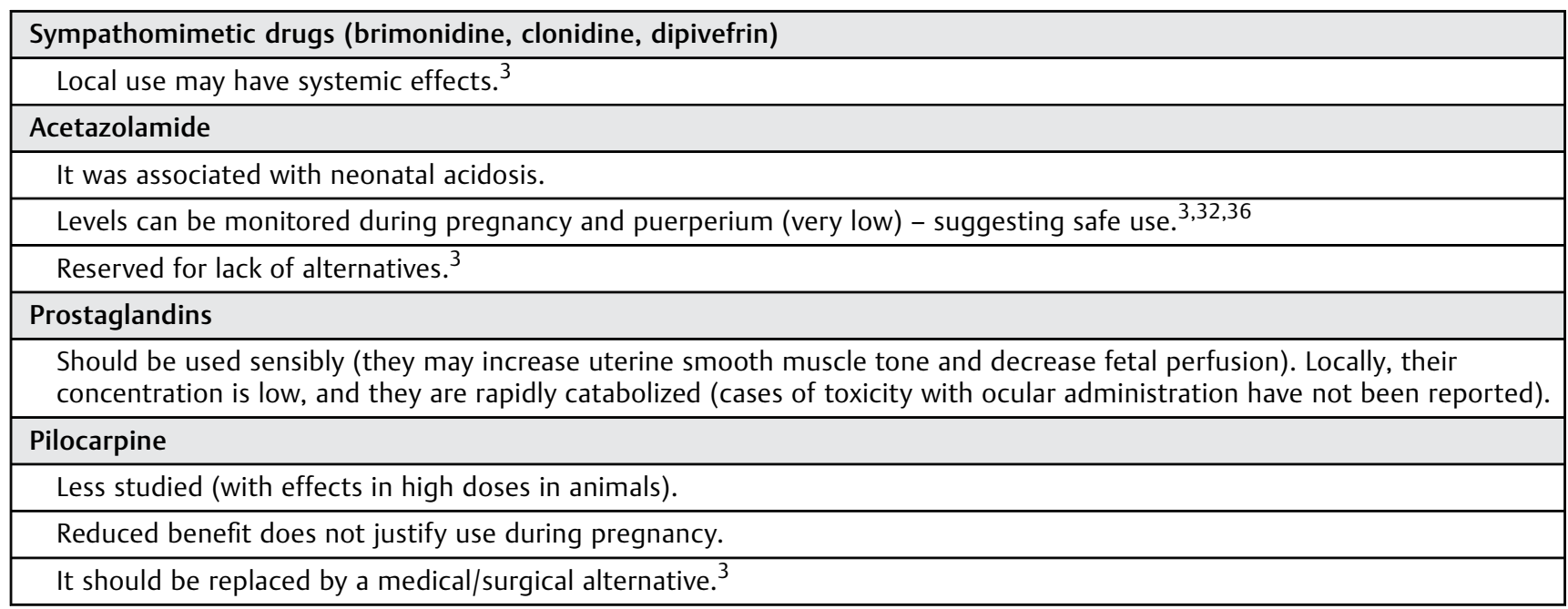

\section{Antibiotics}

The use of ocular antibiotics appears to be safe. The drugs known to be safe during pregnancy include ophthalmological erythromycin, tobramycin and gentamicin, polymyxin $\mathrm{B}$, acyclovir and quinolones. ${ }^{3,4,32}$ Those that should be avoided include chloramphenicol, neomycin, and tetracyclines. ${ }^{3,4}$ The successful use of chloramphenicol has been reported if the dose and duration of the treatment have been followed according to the prescription, and the use of this drug should be discontinued at delivery. ${ }^{32}$

In the case of ocular toxoplasmosis, although the classic pyrimethamine and sulfadiazine therapy has already been used with serum monitoring, spiramycin is recommended as a safe and effective alternative during pregnancy. ${ }^{32}$

\section{Antivirals}

The use of acyclovir is generally well-tolerated by pregnant women, and it has low toxic potential and no adverse effects described during pregnancy. ${ }^{32}$ Conjunctivitis is almost always viral, requiring no antibiotic therapy. ${ }^{3}$

\section{Antihistamines}

The use of antihistamines for allergies is considered safe; ${ }^{32}$ the anti-inflammatory medication (namely cyclosporine) should be used on a pro re nata basis and monitored to avoid adverse effects. $^{32}$

\section{Anti-vascular Endothelial Growth Factor}

Anti-vascular endothelial growth factor (anti-VEGF) ranibizumab (Lucentis, Novartis Pharma SAS, Humingue, France) and aflibercept (Eylea, Bayer Pharma AG, Berlin, Germany) with intravitreal administration are now approved for the treatment of retinal vascular diseases. However, there are few cases of reported use during pregnancy. The decision to use is individualized, with preference to ranibizumab, since it does not cross the placenta. ${ }^{3}$ Intravitreal bevacizumab has already been administered in cases of high-risk pathologies, in a small series, with a good maternal-fetal outcome. ${ }^{37}$

\section{Analgesics|Anesthetics}

No teratogenic effects have been reported with anesthetics or topical analgesics; therefore they are considered safe to use. ${ }^{3}$

\section{Miotics/Mydriatics}

Miotics appear to be safe during pregnancy. Mydriatics, in the amount of occasional drops for examination purposes, are considered safe. For pupillary dilation, although substances such as tropicamide and phenylephrine are contraindicated during pregnancy, their use for diagnostic purposes and in single doses seems to be consensual during pregnancy. ${ }^{3}$ For therapeutic and longer dilatation, scopolamine and atropine are used locally. ${ }^{3}$

The systemic use of phenylephrine, atropine, homatropine and scopolamine has been associated with minor fetal abnormalities, such as inguinal hernia and club foot. ${ }^{38}$

The decision to use medication with potential risks should be explained and discussed with the patient. If administration is required, occlusion of the lacrimal sac (nasolacrimal compression through medial digital pressure on the lower eyelid and lacrimal point occlusion) must be performed to limit the systemic absorption of the medication (-Fig. 1). ${ }^{4}$ As the opening of this point needs the eyelid open, delicate
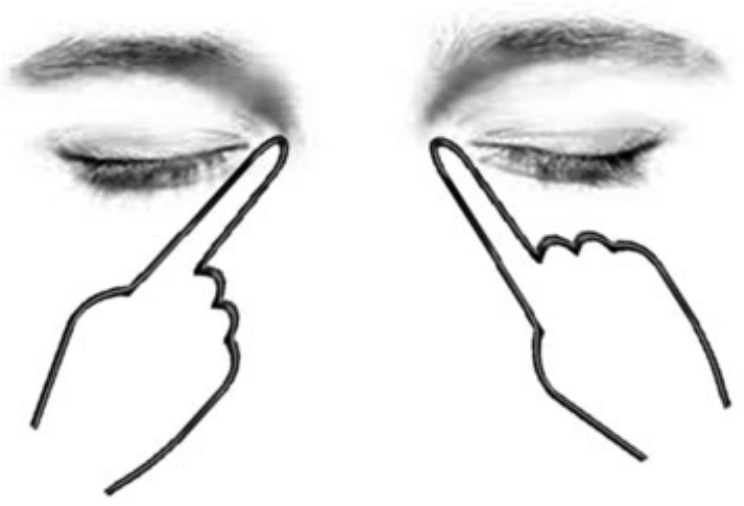

Fig. 1 Manual nasolacrimal occlusion after eye drop instillation. 
closure for one to two minutes can slow down the drainage. The minimum effective dose should be used. ${ }^{4}$ More caution will be required if systemic or topical questionable administration is urgently needed, and the obstetrician should be consulted.

As a general rule, all drugs should be avoided if possible in the first trimester, due to the potential higher risk of teratogenicity in this period. However, this recommendation should not inhibit the prescription of treatments in which the maternal benefit exceeds the fetal risks. Each case should be addressed individually, and, if in doubt, the possible side effects and available therapeutic options should be discussed between the patient and the clinician. ${ }^{32}$ Many drugs have not been specifically approved for use during pregnancy and lactation, and their use in these cases is off-label. Consequently, informed consent with written documentation is advisable. ${ }^{32}$

\section{Diagnostic Agents}

Fluorescein dye crosses the placenta and is present in breast milk for at least 76 hours after administration. To date, there are no published teratogenic effects in animals or humans. ${ }^{38}$ However, in practice, it is avoided during pregnancy unless a threatening vision injury is diagnosed (such as in a vascular membrane of the choroid). ${ }^{39-44}$ It should be avoided in the first trimester and in the puerperium if the baby is undergoing phototherapy (a relevant concentration in the breast milk is detected, with published cases of phototoxicity associated with fluorescein). ${ }^{45}$ Indocyanine green was administered to pregnant women with non-ophthalmologic purposes (such as for the measurement of the hepatic flow), without adverse effects on the mother or fetus. ${ }^{38}$ It does not cross the placenta, and it is unknown if it is present in the breast milk. ${ }^{38}$ Despite the safety record, there is still widespread hesitation about its use during pregnancy. ${ }^{41}$

\section{Oculomotor Pathology}

There are two types of oculomotor pathology: convergence or accommodation insufficiency (which tends to occur more in the third trimester) and oculomotor paralysis. Convergence insufficiency is attributed to changes in the lens. At a point near the eye, diplopia may occur. Oculomotor paralysis may occur in cases of PE due to vasospasm of the cranial nerves, mainly the abducens and the facial nerves (and not so much of the oculomotor nerve). Since its occurrence is rare during routine pregnancies, PE or intracranial pathology must be excluded.

\section{Pregnancy and Childbirth}

In theory, the efforts of labor could be rhegmatogenous (provoking detachments of the retina by tearing) in patients with high myopia. An ophthalmological examination is mandatory before and during pregnancy, and the only recommendation is labor facilitated by an epidural analgesia drug during delivery. If there are previous retinal detachment lesions, a prepartum photocoagulation should be considered. It has been questioned whether these injuries or the existence of a previous surgery should affect the route of delivery. $^{42}$

\section{Are there any Indications for Elective Cesarean?}

Vaginal birth is almost always possible. No significant changes in intraocular pressure during labor have been documented. ${ }^{43}$ Cesarean section is not necessary due to the presence of myopia, peripheral retinal degenerations or after retinal surgery. Nevertheless, up to $2 \%$ of cases of cesarean sections are performed because of an ophthalmologic pathology (usually myopia [57\%] or glaucoma [5\%]). ${ }^{3}$ The recommendations regarding this mode of delivery in women with preexisting ocular disease are not based on evidence, even though cesarean sections are often performed in women with ocular disease. In cases of glaucoma, the rationale would involve increased intraocular pressure, with a potential decrease in ocular perfusion by Valsalva maneuvers performed during a vaginal delivery. The absence of ocular perfusion reduction at delivery and a modest increase in intraocular pressure during Valsalva maneuvers, with a mean of $4 \mathrm{~mm} \mathrm{Hg}$ and a maximum of $12 \mathrm{~mm} \mathrm{Hg}$, have been shown to be insignificant even for damaged optic nerves. ${ }^{3,43}$ For high myopic patients and women with retinal degeneration or post retinal detachment, studies have shown no association between vaginal delivery and new retinal detachment/retinal degeneration regardless of current refractive error or previous vitreoretinal interventions. ${ }^{1,3,44}$ Thus, the fear that the ophthalmological pathology will worsen with vaginal delivery has no recognized justification for any type of ocular pathology. Isolated preexisting ocular disease is not an indication for cesarean section. ${ }^{3}$ In studies comparing attitudes, it was concluded, in the case of women treated for retinal detachment, that the attitude of obstetricians was more favorable to cesarean section, while ophthalmologists recommended spontaneous vaginal delivery. This opinion was influenced by experience in the clinical practice. ${ }^{45,46}$

\section{Conclusion}

Pregnancy is associated with a variety of physiological ocular changes, modifications in existing ocular pathologies and pathological ones. Most of these resolve in the postpartum period, and they can rarely lead to permanent damage in vision.

In the majority of cases, either in new or preexisting diseases, ophthalmologic therapy in this period has reduced contraindications, with more benefits than risks, especially if a topical route of drug delivery is used.

Regarding delivery, even with the expulsive efforts, there are no ophthalmological contraindications to vaginal delivery.

Conflicts of Interest

Authors have no conflicts of interest to declare.

\section{References}

1 Gouveia EB, Conceição PS, Morales MS. [Ocular changes during pregnancy]. Arq Bras Oftalmol 2009;72(02):268-274

2 Samra KA. The eye and visual system in pregnancy, what to expect? An in-depth review. Oman J Ophthalmol 2013;6(02): 87-91

3 Mackensen F, Paulus WE, Max R, Ness T. Ocular changes during pregnancy. Dtsch Arztebl Int 2014;111(33-34):567-575, quiz 576 
4 Chawla S, Chaudhary T, Aggarwal S, Maiti GD, Jaiswal K, Yadav J. Ophthalmic considerations in pregnancy. Med J Armed Forces India 2013;69(03):278-284

5 Altay Y, Altay MM, Demirok G, Balta O, Bolu H. Measurements of pupillary diameter and wavefront aberrations in pregnant women. Scientifica (Cairo) 2016;2016:4129524

6 Riss B, Riss P. Corneal sensitivity in pregnancy. Ophthalmologica 1981;183(02):57-62

7 Akar Y, Yucel I, Akar ME, Uner M, Trak B. Long-term fluctuation of retinal sensitivity during pregnancy. Can J Ophthalmol 2005; 40(04):487-491

8 Schultz KL, Birnbaum AD, Goldstein DA. Ocular disease in pregnancy. Curr Opin Ophthalmol 2005;16(05):308-314

9 Pizzarello LD. Refractive changes in pregnancy. Graefes Arch Clin Exp Ophthalmol 2003;241(06):484-488

10 Efe YK, Ugurbas SC, Alpay A, Ugurbas SH. The course of corneal and intraocular pressure changes during pregnancy. Can J Ophthalmol 2012;47(02):150-154

11 Green K, Phillips CI, Cheeks L, Slagle T. Aqueous humor flow rate and intraocular pressure during and after pregnancy. Ophthalmic Res 1988;20(06):353-357

12 Kara N, Yildirim Y, Tekirdag AI, et al. Effect of body posture on intraocular pressure and ocular perfusion pressure in nonglaucomatous pregnant women. Curr Eye Res 2013;38(01):80-85

13 Kara N, Sayin N, Pirhan D, et al. Evaluation of subfoveal choroidal thickness in pregnant women using enhanced depth imaging optical coherence tomography. Curr Eye Res 2014;39(06):642-647

14 Ataş M, Açmaz G, Aksoy H, et al. Evaluation of the macula, retinal nerve fiber layer and choroid in preeclampsia, healthy pregnant and healthy non-pregnant women using spectral-domain optical coherence tomography. Hypertens Pregnancy 2014;33(03):299-310

15 Ulusoy DM, Duru N, Ataş M, Altınkaynak H, Duru Z, Açmaz G. Measurement of choroidal thickness and macular thickness during and after pregnancy. Int J Ophthalmol 2015;8(02):321-325

16 Sayin N, Kara N, Pirhan D, et al. Subfoveal choroidal thickness in preeclampsia: comparison with normal pregnant and nonpregnant women. Semin Ophthalmol 2014;29(01):11-17

17 Dadaci Z, Alptekin H, Oncel Acir N, Borazan M. Changes in choroidal thickness during pregnancy detected by enhanced depth imaging optical coherence tomography. Br J Ophthalmol 2015;99(09):1255-1259

18 Karki P, Malla P, Das H, Uprety DK. Association between pregnancy-induced hypertensive fundus changes and fetal outcomes. Nepal J Ophthalmol 2010;2(01):26-30

19 Gupta A, Kaliaperumal S, Setia S, Suchi ST, Rao VA. Retinopathy in preeclampsia: association with birth weight and uric acid level. Retina 2008;28(08):1104-1110

20 Kaliaperumal S, Setia S, Gupta A, Rao VA. Fetal birthweight and diastolic blood pressure: association with retinopathy in severe preeclampsia. Eur J Ophthalmol 2008;18(05):809-812

21 Erbagci I, Karaca M, Ugur MG, Okumus S, Bekir NA. Ophthalmic manifestations of 107 cases with hemolysis, elevated liver enzymes and low platelet count syndrome. Saudi Med J 2008;29 (08):1160-1163

22 Sim DA, Sheth HG, Kaines A, Tufail A. Punctate inner choroidopathy-associated choroidal neovascular membranes during pregnancy. Eye (Lond) 2008;22(05):725-727

23 Best RM, Chakravarthy U. Diabetic retinopathy in pregnancy. Br J Ophthalmol 1997;81(03):249-251

24 Morrison JL, Hodgson LA, Lim LL, Al-Qureshi S. Diabetic retinopathy in pregnancy: a review. Clin Experiment Ophthalmol 2016; 44(04):321-334
25 Lövestam-Adrian M, Agardh CD, Aberg A, Agardh E. Pre-eclampsia is a potent risk factor for deterioration of retinopathy during pregnancy in Type 1 diabetic patients. Diabet Med 1997;14(12): 1059-1065

26 Lauszus F, Klebe JG, Bek T. Diabetic retinopathy in pregnancy during tight metabolic control. Acta Obstet Gynecol Scand 2000; 79(05):367-370

27 Rabiah PK, Vitale AT. Noninfectious uveitis and pregnancy. Am J Ophthalmol 2003;136(01):91-98

28 Chiam NP, Hall AJ, Stawell RJ, Busija L, Lim LL. The course of uveitis in pregnancy and postpartum. Br J Ophthalmol 2013;97(10): 1284-1288

29 Garweg JG, Scherrer J, Wallon M, Kodjikian L, Peyron F. Reactivation of ocular toxoplasmosis during pregnancy. BJOG 2005; 112(02):241-242

30 Kump LI, Androudi SN, Foster CS. Ocular toxoplasmosis in pregnancy. Clin Experiment Ophthalmol 2005;33(05):455-460

31 Shields CL, Shields JA, Eagle RC Jr, De Potter P, Menduke H. Uveal melanoma and pregnancy. A report of 16 cases. Ophthalmology 1991;98(11):1667-1673

32 Chung CY, Kwok AK, Chung KL. Use of ophthalmic medications during pregnancy. Hong Kong Med J 2004;10(03):191-195

33 Ness T, Paulus W. [Eye and pregnancy.]. Ophthalmologe 2010; 107(09):863-872, quiz 873

34 Labetoulle M, Gendron G, Offret H. [Eyedrops in children and pregnant or breast-feeding woman: why so many difficulties?] J Fr Ophtalmol 2009;32(02):135-150

35 Ho JD, Hu CC, Lin HC. Antiglaucoma medications during pregnancy and the risk of low birth weight: a population-based study. Br J Ophthalmol 2009;93(10):1283-1286

36 Lee AG, Pless M, Falardeau J, Capozzoli T, Wall M, Kardon RH. The use of acetazolamide in idiopathic intracranial hypertension during pregnancy. Am J Ophthalmol 2005;139(05):855-859

37 Tarantola RM, Folk JC, Boldt HC, Mahajan VB. Intravitreal bevacizumab during pregnancy. Retina 2010;30(09):1405-1411

38 Sheth BP, Mieler WF. Ocular complications of pregnancy. Curr Opin Ophthalmol 2001;12(06):455-463

39 Halperin LS, Olk RJ, Soubrane G, Coscas G. Safety of fluorescein angiography during pregnancy. Am J Ophthalmol 1990;109(05): 563-566

40 Olk RJ, Halperin LS, Soubrane G, Coscas G. Fluorescein angiography-is it safe to use in a pregnant patient? Eur J Ophthalmol 1991; 1(02):103-106

41 Fineman MS, Maguire JI, Fineman SW, Benson WE. Safety of indocyanine green angiography during pregnancy: a survey of the retina, macula, and vitreous societies. Arch Ophthalmol 2001; 119(03):353-355

42 Inglesby DV, Little BC, Chignell AH. Surgery for detachment of the retina should not affect a normal delivery. BMJ 1990; 300(6730):980

43 Meshi A, Armarnik S, Mimouni M, et al. The effect of labor on the intraocular pressure in healthy women. J Glaucoma 2017;26(01): 59-64

44 Ataş M, Duru N, Ulusoy DM, et al. Evaluation of anterior segment parameters during and after pregnancy. Cont Lens Anterior Eye 2014;37(06):447-450

45 Chiu H, Steele D, McAlister C, Lam WC. Delivery recommendations for pregnant females with risk factors for rhegmatogenous retinal detachment. Can J Ophthalmol 2015;50(01):11-18

46 Papamichael E, Aylward GW, Regan L. Obstetric opinions regarding the method of delivery in women that have had surgery for retinal detachment. JRSM Short Rep 2011;2(04):24 